\title{
A Comparative Study of the Influence of Different Types of Polymers on Viscosity Index and Pour Point of Iraqi Base Oils
}

\author{
Rusul F. Abdul-saheb and Muhanned A. Mohammed
}

Al-Nahrain University

\begin{abstract}
In this study, the effects of blending the un-branched acrylate polymer known as Poly (n-decyl acrylate), and the branched acrylate polymer known as Poly (iso-octyl acrylate), on the viscosity index (VI), and the pour point of the Iraqi base stocks 40 , and 60 respectively, were investigated. Toluene was used as a carrier solvent for both polymer types. The improvement level of oils (VI, \& pour point) gained by blending the oil with the acrylate derived polymers was compared with the values of (VI, and pour point) gained by blending the oil with a commercial viscosity index, and pour point improver. The commercial lubricant additive was purchased and used by Al-Daura Refineries. It consisted of an un-known olefin copolymer dissolved in an un-known carrier solvent. All polyacrylate derivatives and the commercial lubricant additive named HITEC5748 were blended with each type of oil in weight percentage of $(2,4,6,8, \& 10) \mathrm{wt}$. \%. The result of the study was that the improvement in the viscosity index and the pour point of both base stock types was higher when using the polyacrylate derivatives than when using the commercial olefin copolymer additive.
\end{abstract}

Keywords: Lubricants, Viscosity index, Pour point, Pol acrylates

Received on 02/12/2018, Accepted on 22/01/2019, published on 30/09/2019

https://doi.org/10.31699/IJCPE.2019.3.2

\section{1- Introduction}

Machines perform a window for the development of the world, because of their entry in wide fields of human life aspects including; transportation fields such as automobiles, and trains, power generation fields such as turbines, boilers, compressors, and many more other applications [1]. Machines during their usage suffer corrosion, tear, and friction forces leading to machine cracks, and system failures. As a result, the protection of machines against degradation became the main consideration, and the need for lubrication appeared [2].

A Lubricant can be defined as a substance utilized in smoothing the movement of solid bodies through decreasing friction, heat due to friction, and corrosion over the interacting surfaces, thus they prolong machine life period [3]. Lubrication itself is not a newly created concept, hundreds of years ago animal fats were used for the purpose of lubrication. The basic principle of lubrication is the prevention of metal-to-metal contact by introducing a fluid or fluid-like material layer known as a lubricant between the interacted surfaces [4].

Lubricants can be categorized according to their physical appearance in to liquid lubricants including the lubricants that are derived from petroleum oils, synthetic oils or from biological sources, Semi-solid lubricants which are liquid suspended in a solid matrix of additives and thickener like Greases, and Solid lubricants which are films of solid material composed of organic or inorganic compounds like graphite [5].
The present day commercial lubricants are combinations of base oils and additives. The base oil should pass through de-waxing, and solvent extraction processes prior to mixing with the additives, in order to reduce both wax and polyaromatic content. Where wax prevents free movement at lower temperatures [6], [7], while polyaromatics reduce the stability of oils viscosity to temperature variation [7]. The additives are mostly organic compounds within special structures that are added to base oils in small quantities to upgrade their characteristic including viscosity, viscosity index, and pour point [8]. The un-used lubricant contains from (71 to 96 wt. \%) base oil, and the rest are additives [9].

The viscosity of an oil is a major concern in selecting the proper lubricant for a given application, since it increases with temperature reduction, and reduces with temperature increasing. The value of viscosity should be high enough to ensure good lubrication but not very high so the friction losses are increased [10]. The viscosity index (VI) is a calculated dimensionless number represents the sensitivity of oils viscosity to temperature, in other words, the VI represents oils viscosity change with temperature variation [11]. Higher VI number expresses low viscosity dependence on temperature which is preferred [12].

Viscosity index improvers (VIIs) are high molecular weight long chain oil soluble polymers that are added to lubricants to control their rate of viscosity variation with temperature. 
They have a small effect on lubricant consistency at low temperatures while their molecules transform from tight coils to an open configuration at higher temperatures thus, exerting a larger thickening influence on lubricant at higher temperatures than they do at lower temperatures [13].

The Pour point of the oil is the minimum temperature at which oil still can circulate; lower pour point oils are preferred. The formulation of crude oil derives contains waxes naturally. The wax molecules combine with each other and crystallize. Furthermore, the wax crystals precipitate forming a gel material that restricts oil flow at low temperatures. The pour point depressants are added substances that lower the pour point of oil through meddling with wax crystallization [14].

Margareth et al. [2010] verified the effects of VI modifiers on the consistency of lubricants, also discussed fuels economics. 8 types of additives were examined in the study. They concluded that the multigrade viscosity fuels are better than the monograde viscosity fuels. It was also found that the fuel consumption increases linearly with lubricant high temperature, high shear viscosity, and lower friction power can be reached through using lower viscosity multigrade oil in motor operation [15].

Salah et al. [2012] Produced and assessed six copolymers derived from polyacrylates to be used as lubricant additives for viscosity index improvement. The molecular weight of the produced polymers was calculated to have values between 140,000 and 236,000 . Blends of different weight fractions vary from $0.5 \%$ to $3 \%$, for each copolymer was produced, then examined as lube oil VI improvers. They concluded that all produced materials were efficient lube oil VI improvers, and the effectiveness increases by increasing either their molecular weight or their alkyl chain length. The effectiveness could also be raised by raising the concentration of the additives in the base oil. There were no reflection points in the examined range of concentrations [16].

Joshua et al. [2016] prepared and evaluated the extremely branched polyethylene as the viscosity index, and friction improvers. The prepared materials proved a dual function. These compounds reduced the friction and the viscosity index of the lubricant. Changing the molecular weight, polarity and topology of the branched polyethylene displayed respectable changes in lubricant performance. This study supported the future development of lubricants and the design of new scientific polymers [17].

Sheida et al. [2016] studied the possibility of improving the properties of lubricants that are mainly manufactured from crude oils or from synthetic hydrocarbon mixes by using Nanoparticle additives. Nanoparticles are added to the base stock to enhance many characteristics of anti-oxidation probability, tribological properties, wear and friction resistance and thermal characteristics. This research shows studies on Nano-additives in the industry of lubricants.
The study includes both general view on base oils and traditional lubricants modifiers and a more specific view on the employment of Nano-particles. In the end, this research has big benefits for the future use of nanoparticles in the lube oil industry [18].

Neveu et al. [2016] this article is a general overview of Poly alkyl methacrylates (PAMA), including their manufacturing pathway to the economics of their usage in lubrication fields [19].

Mohammad et al. [2018] Investigated the rheological attitude of Nano-lubricants containing (SiO2/5W50). The Nano-lubricant consisted of $40 \% \mathrm{MWCNT}$, and $60 \%$ SiO2/5W50 nanoparticles.

The dynamic consistency of lubricant was determined for temperature domain between $5{ }^{\circ} \mathrm{C}$ and $55^{\circ} \mathrm{C}$, the additive volume $\%$ was between 0 , and 1 , and the average shear of the fluid varied from 50 to $800 \mathrm{rpm}$.

The study of Nano fluids rheological attitude against its shear stress proved that the Nano-lubricant is a nonNewtonian fluid that follows Bingham shear thinning behavior for low temperatures while the behavior is turned at high temperatures. A correlation for relative dynamic viscosity estimation was proposed, and it showed a proper accuracy [20].

The main purpose of this research is to develop the properties of lubricants, by using different additives. Then to find the optimum weight fractions of each additive which enhance the properties of the lubricant such as, viscosity index, and pour point.

\section{2- Experimental Work}

\subsection{Materials and Chemicals}

a. The Iraqi base-stock

The two types of base stock were obtained from AlDaura Refineries, as products for the vacuum distillation process. The properties of base oils are shown in Table $\mathbf{1}$.

Table 1. The used Iraqi base stocks, and their characteristics

\begin{tabular}{lcc}
\hline Property & Base- stock 40 & Base- stock 40 \\
\hline $\begin{array}{l}\text { Kinematic Viscosity at } \\
40{ }^{\circ} \mathrm{C}, \mathrm{cSt}\end{array}$ & 14.2 & 63.4 \\
Kinematic Viscosity at & 3.36 & 8.5 \\
$100{ }^{\circ} \mathrm{C}, \mathrm{cSt}$ & \\
Viscosity Index (VI) & 106 & 108 \\
Specific gravity at & 0.85 & 0.88 \\
$\left(15.6^{\circ} \mathrm{C} / 15.6^{\circ} \mathrm{C}\right)$ & & \\
API gravity & 34.97 & 29.29 \\
Pour point, ${ }^{\circ} \mathrm{C}$ & -9 & -6 \\
\hline
\end{tabular}




\section{b. Chemicals}

The chemicals used were HITEC5748 commercial olefin copolymer, in a liquid state, brown color, of 955 cSt. $100{ }^{\circ} \mathrm{C}$ kinematic viscosity, and a shear stability index of 155(China), Poly (n-decyl Acrylate) a white powder with a purity of $95 \%$, and a density of $2.42 \mathrm{gm} . /$ cm3 (China), Poly (iso-octyl Acrylate) a transparent powder with a purity of $98 \%$, and a density of $1.85 \mathrm{gm} . /$ $\mathrm{cm} 3$ (China), and Toluene, liquid with a vapor pressure of $22 \mathrm{mmHg}$, and 99.8 purity (China).

\subsection{Analysis Instruments}

\section{a. Kinematic Viscosity Equipment}

The Tamson TV4000 equipment is designed to determine the kinematic viscosity of blends at steady temperatures according to the ASTM D445 test method. The instrument consists of a transparent glass viscometer and a controlled temperature oil bath. The viscometer is a simple apparatus valid in different shapes, and sizes. Their selection depends upon the viscosity of the liquid, more viscous liquids requires wider viscometers. The bath chamber is made of stainless steel with one transparent glass window. The machine temperature range varies from $10^{\circ} \mathrm{C}$ to $230^{\circ} \mathrm{C}$ with an accuracy of $\pm 0.1^{\circ} \mathrm{C}$. the device contains eight holes for subjecting viscometer holders. The working voltage of the instrument is $230 \mathrm{~V}$.

\section{b. Pour Point Tester}

This instrument works like a refrigerator; it reduces the temperature of the sample to estimate their freezing temperatures for Pour point measurement according to ASTM D97 test method. The apparatus model is Hamco Cloud and Pour Point Apparatus. The device temperature range varies from zero to $-51^{\circ} \mathrm{C}$, it has four jacket baths, and each one is preset at a different temperature for convenient pour point testing. Bath hoods are covered with a synthetic sponge top plate. Bath cabinet and interior housing are constructed of stainless steel with a removable top plate and $13 \mathrm{~mm}$ cork.

\subsection{Experimental procedure}

a. The Preparation Steps of HITEC5748 Additive Blends

The used experimental instruments including (beakers, and viscometers) should be clean, dry, and at room temperature prior to their usage.

The weight of the beaker was measured by using a sensitive balance, since the beaker is only a container, and its weight should be neglected during the preparation of samples. Then the additive was introduced into the beaker for the desired wt. \%, the base oil was introduced into the beaker after.
The beaker that contains both base oil and additive was then adjusted over a hot plate magnetic stir to get homogeneous liquid blends of base-stock and polymeric additives. The samples were blended for 40 minutes at a temperature of $70^{\circ} \mathrm{C}$.

The well-mixed samples are allowed to settle, and to get to room temperature before examining the effects of the additive on the VI, and pour point of the oil according to the ASTM test methods procedures.

b. The preparation steps of poly (n-decyl acrylate), and poly (iso-octyl acrylate) additives blends

Both poly (n-decyl acrylate), and poly (iso-octyl acrylate) additives were dissolved in toluene in order to make them in liquid form before blending them with the oils. Each additive was mixed with the toluene in weight percentage of $60 \%$ polymer, and $40 \%$ solvent separately.

The mixture was then adjusted over a hot plate magnetic stir for a period of $4 \mathrm{hr}$. at a temperature of $60{ }^{\circ} \mathrm{C}$.

The prepared mixtures were left at room temperature for many days to ensure their solubility, where no precipitates or impurities appeared. After the solubility and homogeneity of mixtures were checked, the solutions were blended with base oil following the same steps of HITEC5748 additive mentioned in (2.3.a) section.

\section{3- Results, and Discussion}

\subsection{Effect of HITEC5748 Additive}

This olefin copolymer was selected to be a reference additive to evaluate acrylate derived polymers efficiency as VI, and pour point improvers. Fig. 1 observes the effect of HITEC5748 addition on the VI of base stock 40, and 60 respectively. The behavior of both base stocks is the same that is increasing the wt. \% of additive leads to an increase in VI.

The olefin copolymer molecules are arranged to stay as tight coils at low temperatures so that, there presence doesn't affect the viscosity of oil. While at high temperatures, their presence doesn't affect the viscosity of the oil. While at high temperatures their molecules expand forming open configurations that raise the viscosity of the oil [21].

The VI represents the stability of oils viscosity against temperature change. The higher the VI value gained is better since, it indicates low sensitivity to temperature change [22]. The VI of base stock 40 is more affected by the presence of HITEC5748 than base stock 60 due to the difference in the viscosity between base 40 , and base 60 where, lower viscosity stock is better since, lower viscosity values reached at cold conditions which are an essential requirement, also more fluidity means more capability of olefin to extend at higher temperatures [23].

The obtained mixtures are suitable to be used as motor lubricants where VI is sufficient to establish lubrication also the formed mixtures have good fluidity. 


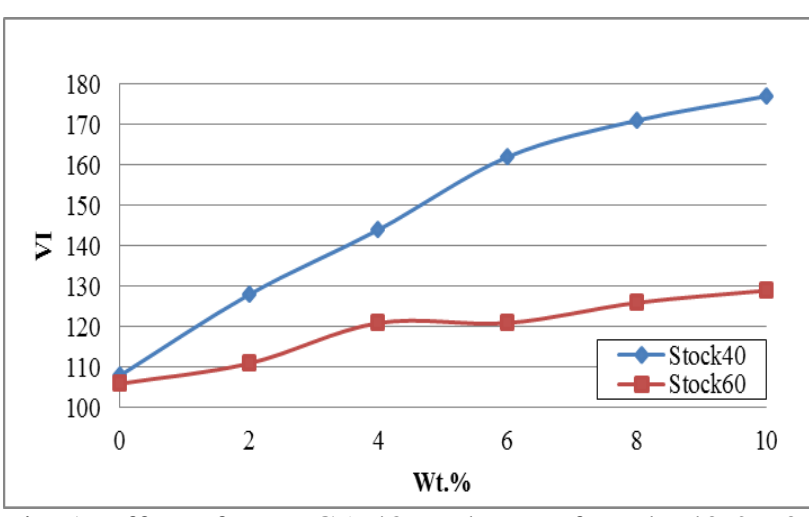

Fig. 1. Effect of HITEC5748 on the VI of stocks 40 \& 60

Fig. 2 observes the effect of HITEC5748 addition on the pour point of base stock 40, and 60 respectively. The figure shows that both stock types are affected by the addition of HITEC5748 olefin copolymer only there behaviors against it are different.

Where the pour point of base stock 40 reduces by the addition of copolymer and reaches its minimum value of 21 at 2 wt. $\%$ of the additive, the molecules of additive combine with the wax molecules that are already present in mineral base oils and suspend these combinations in the bulk fluid, which restricts the formulation of big wax crystals leading in the end to the reduction in the pour point [11], [24]. At 4 wt. \% the behavior of base stock 40 is reflected since, increasing the wt. \% of additive causes an increase in the pour point, this inversion is attributed to the increase in the molecular weight of the additive, density of additive, and viscosity of the blends by the addition of the olefin i.e. the saturation with the additive occurs, leading to pour point increasing as a result which is not favorable [24].

While for base stock 60 , the pour point keeps reducing by the addition of HITEC 5748 copolymer, and it reaches its minimum value of -12 at $8 \mathrm{wt}$. $\%$ of the additive. There was no inversion noticed in this case, because lower viscosity oils are more affected by the action of additives [23].

Economically, the base stock 40 is better than base stock 60 because lower pour points can be earned with fewer amounts of additive.

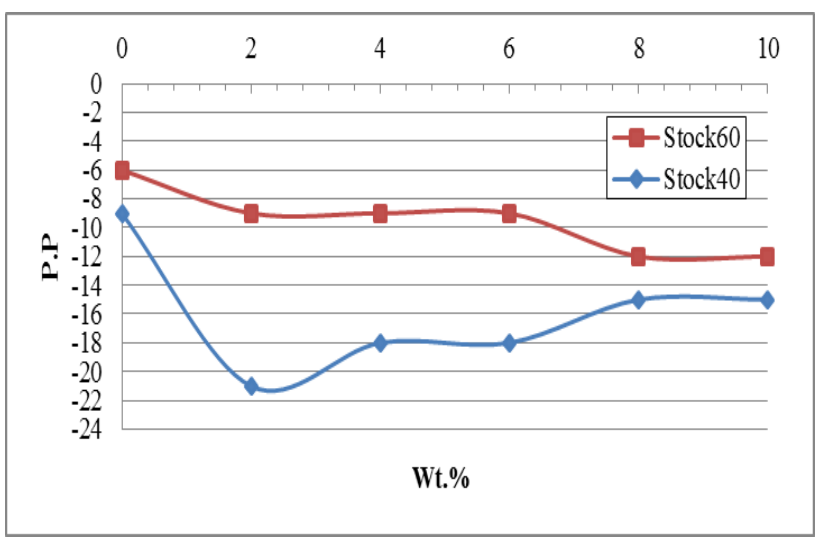

Fig. 2. Effect of HITEC5748 on the pour point of stocks $40 \& 60$

\subsection{Effect of Poly (n-decyl) acrylate Additive}

Fig. 3 observes the effect of Poly (n-decyl acrylate) addition on the VI of Base stock 40, and 60 respectively. In general, VI increased with wt. \% increase.

This increase in VI is attributed to the structure of the additive, where it belongs to the Poly Alkyl Methacrylate (PAMA) family. The molecules of this family members are hydrocarbons that have the ability to extend forming big size arrangements that raise the viscosity of the oil at higher temperatures i.e. increase the stability of oil viscosity against temperature change [25], [26].

The VI increased from 108 to 186 for base stock 40, while increased from 106 to 142 for base stock 60. The base stock 40 is more affected by the presence of Poly (ndecyl acrylate) than Base stock 60. This difference between VI readings is because of the difference in the viscosity of base stocks, since lower viscosity sample is a more suitable environment for viscosity index improvers [23].

The increasing manner in the viscosity index of both base stock types 40, and 60 after the addition of Poly (ndecyl acrylate) copolymer is similar to the VI increasing manner of HITEC5748 olefin copolymer additive, but the VI values are higher. This difference in VI is because of the presence of ester functional group in the structure of the monomers that form the Poly (n-decyl acrylate) copolymer, which categorized to be more active than the double bond carbon atoms contained in the monomers of the commercial olefin copolymer [26].

The obtained mixtures properties are acceptable in motor lubricants where VI is sufficient to establish lubrication also the formed mixtures have good fluidity.

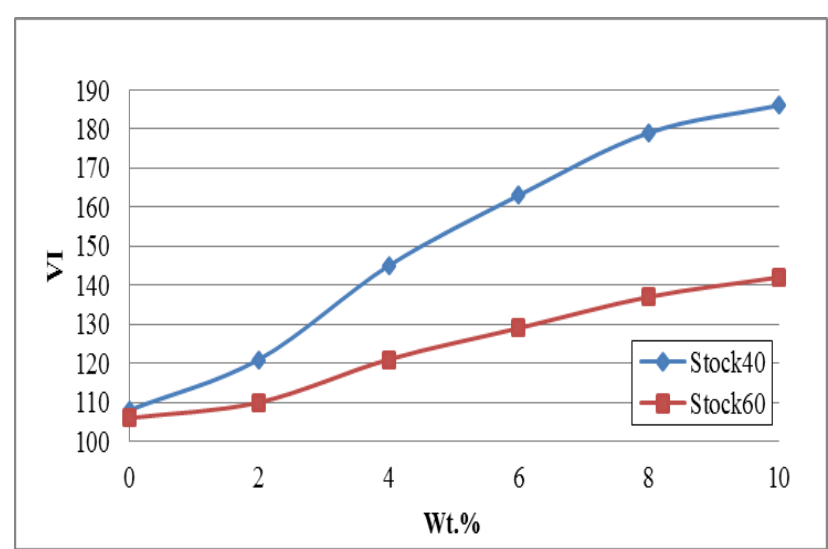

Fig. 3. Effect of Poly (n-decyl acrylate) copolymer on the VI of Stocks $40 \& 60$

Fig. 4 shows the effect of Poly (n-decyl acrylate) addition on the pour point of base stock 40, and 60 respectively.

The figure shows that both stock types are affected by the addition of Poly (n-decyl acrylate) copolymer. The pour point of base stock 40 reduced by the addition of Poly (n-decyl) acrylate copolymer and reached its minimum value of -24 at 10 wt. $\%$. 
While for base stock 60 , the pour point reduced by the addition of copolymer and reached a minimum value of 15 at 6 wt. $\%$ of the additive, then the pour point remains fixed (-15) against the further addition of the additive due to the saturation of base oil with the additive where its effect reached the maximum possible dispersing efficiency.

The copolymer can be described as an efficient pour point dispersant since, it combines with the soot and wax molecules presented in base stock, and keeps them suspended in the bulk fluid, which interferes the formulation and precipitation of wax crystals network that absorbs lubricant and forms gelling in the oil, leading in the end to increase the fluidity of oil, and reduction in pour point value [27].

It can be concluded that for the pour point, the response to Poly (n-decyl acrylate) of base stock 40 is greater than that of base stock 60 since, the lower viscosity oil has more fluidity and reaches lower temperatures before getting freeze than the viscous one [23].

Economically, the base stock 40 is better than base stock 60 because lower pour points can be earned with fewer amounts of additive.

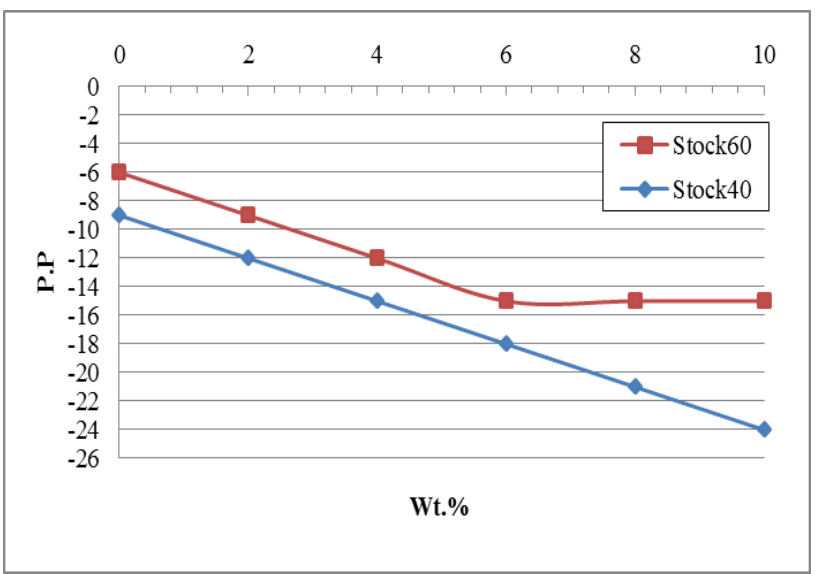

Fig. 4. Effect of Poly (n-decyl acrylate) copolymer on the pour point of stocks $40 \& 60$

\subsection{Effect of Poly (iso-octyl acrylate) Additive}

Fig. 5 displays the effect of Poly (iso-Octyl acrylate) addition on the VI of Base stock 40, and 60 respectively. The VI of both base oils increased with additive wt. \% increase.

This increase in VI is attributed to the considerable thermal stability of the Poly (iso-Octyl acrylate) copolymer, and its resistance for thermal degradation, thus increasing this copolymer concentration in the base oil reduces oils sensitivity to temperature change [25].

By the addition of Poly (iso-Octyl acrylate) copolymer, the VI increased from 108 to 200 for base stock 40, while increased from 106 to 150 for base stock 60 .

The base stock 40 is more affected by the presence of the additive than stock 60, following the same behavior of [HITEC5748, and Poly (n-decyl acrylate)] additives.
The viscosity difference between base oils is the reason for the gained VI difference. Lower viscosity base oil is more suitable to assist the VI improver to work [20], and since the base stock 40 has a lower viscosity than base stock 60 , it was already expected to have higher VI values when being mixed with the suitable additive.

The viscosity index of both base stock types 40 , and 60 increase after the addition of Poly (iso-octyl acrylate) copolymer in a manner close to Poly (n-decyl acrylate) copolymer additive, only with higher VI values. This difference in VI is because of the difference in the structure between the two additives where the monomers of Poly (iso-octyl acrylate) copolymer are branched hydrocarbons with ester functional group. The branched hydrocarbon chains increase the capability of a polymer to improve the VI of an oil, due to their ability to expand forming big size structures that fill the bulk fluid at higher temperatures [27].

The obtained mixtures properties are acceptable in motor lubricants where VI is sufficient to establish lubrication also the formed mixtures have good fluidity.

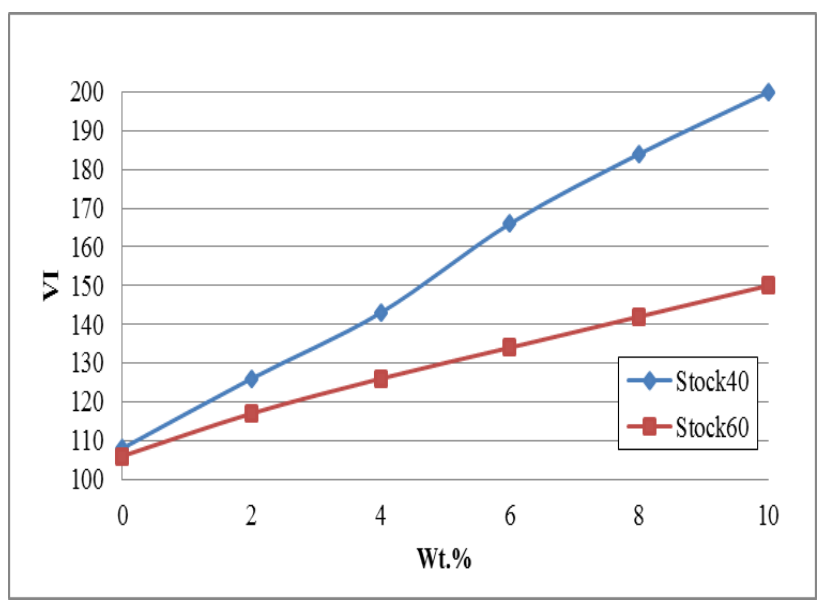

Fig. 5. Effect of Poly (iso-octyl acrylate) copolymer on the VI of Stocks $40 \& 60$

Fig. 6 shows the effect of Poly (iso-octyl acrylate) addition on the pour point of base stock 40, and 60 respectively. The figure shows that both stock types are affected by the addition of copolymer whrer, the pour point reduced with wt.\% increase.

The reduction in the value of pour point is attributed to the structure of the monomers that form the Poly (isooctyl acrylate) copolymer. The monomers consist of a hydrocarbon part that combines with the impurities (soot, wax, combustion products), and a non-pollar ester part that keeps those impurities suspended in the bulk base stock, leading to the increase in the fluidity of oil at lower temperatures i.e. reduction in the pour point of the oil [28].

The pour point of base stock 40 reduced with the addition of Poly (iso-octyl acrylate) copolymer and keeps reducing as the wt. \% increases. 
It reached a minimum value of -27 at 8 wt. $\%$ of the additive, then the additive efficiency as a pour point dispersant reduces at $10 \mathrm{wt}$. \% of copolymer since, the pour point increased to -24 due to oil saturation with an additive which reduced the fluidity, and increased the pour point as a result.

While for base stock 60 , the pour point reduced by the addition of copolymer and reached minimum value of -18 at 8 wt. $\%$ of the additive, then the pour point remains fixed (-18) against the further addition of the additive, the steady value of pour point also indicates saturation of oil with additive [21].

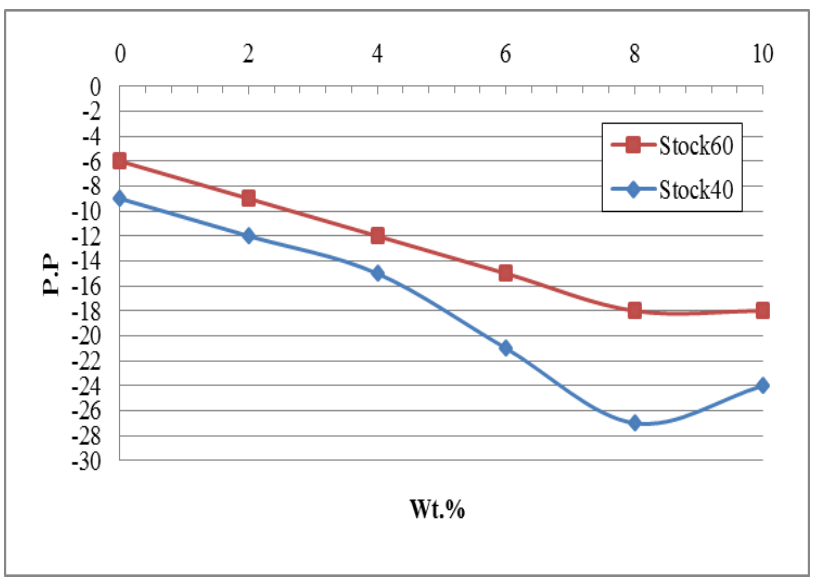

Fig. 6. Effect of poly (iso-octyl acrylate) copolymer on the pour point of stocks $40 \& 60$

\section{4- Conclusion}

The two acrylates derived polymers have shown a good VI, and pour point improvement levels. They were proved to be more efficient than the commercial olefin copolymer. The branched acrylate derived copolymer was better than the un-branched one. The lower viscosity Iraqi base oil is more affected by the presence of additives.

The optimum weight fraction of poly (iso-octyl acrylate) additive is $10 \mathrm{wt}$. $\%$ for both base stock 40 , and base stock 60 , where the VI is 200 , and 150 respectively, while the pour point is -24 and -18 respectively.

For Poly (n-decyl acrylate) additive, the optimum weight fraction is also $10 \mathrm{wt}$. \% for base stock 40 , and base stock 60 , where the VI is 186 , and 142 respectively, while the pour point is -24 , and -15 respectively.

For HITEC 5748 additive, the optimum weight fraction is $6 \mathrm{wt}$. $\%$ for base stock 40 , and $8 \mathrm{wt}$. $\%$ for base stock 60, where, the VI is 177 and 129 respectively while the pour point is -18 and -12 respectively. Economically, the base stock 40 is better than base stock 60 because higher VIs and lower pour points can be earned with fewer amounts of additive.

\section{Acknowledgement}

We express our great appreciation for Al-Daura refineries, and the Department of Chemical Engineering at the University of Nahrain, for their efforts in facilitating the task of research.

\section{References}

[1] Ludema, K.C. "Friction, Wear, Lubrication, A Textbook in Tribology", CRC Press L.L.C., 1996.

[2] Rob Heverly "Lubricant Additives", R. T. Vanderbilt, Company, Inc., Houston, 2012.

[3] Stevens, C., and Roland Verhé "Renewable Bioresources: Scope and Modification for Non-Food Applications", John Wiley \& Sonce, Ltd, Chichester, 2004.

[4] Mortier, R. M., Fox, M. F., and Orszulik, S. T. "Chemistry and Technology of Lubricants" Springer, Dordrecht, 3rd Edition, 2010.

[5] Pranab, G., Das Tapan and Das Moumita, 2011, "Evaluation of Poly (acrylates) and their copolymer as viscosity modifiers", Res. J. Chem. Sci., Volume 1, Issue 3,pp.18-25.

[6] Abdul-Halim A. Mohammed, and Noor S. Akram, 2010, "The Effect of Operating Conditions of Urea Dewaxing on the Pour Point of Light Lubricating Oil”, Iraqi Journal of Chemical and Petroleum Engineering, Vol.11 No.1, PP 59-63.

[7] Abdul-Halim A.-K. Mohammed, Hussain K. Hussain, and Rafal J. Sadiq, 2007, "The Effect of Solvent Extraction of Light Lubricating Oil on Viscosity Index and Chemical Composition", Iraqi Journal of Chemical and Petroleum Engineering, Vol.8, No.4, PP.1-12.

[8] Wang, Y., and Eli, W., 2010, "Synthesis of Biodegradable High-Alkali Magnesium Oleate Detergent", Ind. Eng. Chem. Res., Volume 49, pp.25892592.

[9] Ghiyath A. R. Rassoul and Laith S. Mahmmoud, 2010, "Treating The Used Automobiles Oils Using Solvents", Iraqi Journal of Chemical and Petroleum Engineering, Vol. 11, No.3, PP. 9-14.

[10] Nehal S. Ahmed, Amal M. Nassar, 2009, "Lubricating Oil Additives Based on Poly alkyl polyamines", International Journal of Polymeric Materials and Polymeric Biomaterials, Volume 58, Issue 3, pp. 170-198.

[11] Rios, M.A., S.N. Santiago, A.A. Lopes, and S.E. Mazetto, 2010, "Antioxidative Activity of 5-nPentadecyl-2-tert-butylphenol Stabilizers in Mineral Lubricant Oil", Energy \& Fuels, Volume 24, Issue 5, pp.3285-3291.

[12] Pospíšil, J., 1995, "Polysoaps, Stabilizers, Nitrogen-15 NMR, Advances in Polymer Science", Volume 124, Issue 6, pp.87-189.

[13] Bloch, H. P. "Practical Lubrication for Industrial Facilities", The Fairmont Press, Inc., Lilburn, 2000.

[14] Furniss, B. S., A. J. Hannaford, P. W. G. Smitch, and A. R. Tatchell, "Vogel's Textbook of Practical Organic Chemistry", 5th Edition, New York, 1989.

[15] Margareth Judith Souza de Carvalho, Peter Rudolf Seidl, Carlos Rodrigues Pereira Belchior, José Ricardo Sodré, 2010, "Lubricant viscosity and viscosity improver additive effects on diesel fuel economy", Tribology International, Volume 43, Issue 12, Pages 2298-2302.

[16] Salah A. Mohamad, Nehal S. Ahmed, Saeed M. Hassanein, Ahmed M. Rashad, 2012, "Investigation of polyacrylates copolymers as lube oil viscosity index improvers", Journal of Petroleum Science and Engineering,Volume 100, Pages 173-177. 
[17] Joshua W. Robinson, Yan Zhou, Jun Qu, J. Timothy Bays, Lelia Cosimbescu, 2016, "Highly branched polyethylenes as lubricant viscosity and friction modifiers", Reactive and Functional Polymers, Volume 109, Pages 52-55.

[18] Sheida Shahnazar, Samira Bagheri, Sharifah Bee Abd Hamid 2016, "Enhancing lubricant properties by nanoparticle additives", International Journal of Hydrogen Energy, Volume 41, Issue 4, Pages 3153-3170.

[19] C. D. Neveu, R. Sondjaja, T. Stöhr K. Schimossek, N. J. Iroff, "Lubricant and Fuel Additives Based on Polyalkylmethacrylates", Reference Module in Materials Science and Materials Engineering, 2016.

[20] Mohammad Hemmat Esfe, Ali Akbar Abbasian Arani, 2018, "An experimental determination and accurate prediction of dynamic viscosity of MWCNT(\%40)-SiO2(\%60)/5W50 nano-lubricant", Journal of Molecular Liquids, Volume 259, Pages 227$\underline{237 .}$

[21] Obasi, A.U, Udeagbara, S.G, Anusiobi, O.J., 2014, "Effect of Additives on the Performance of Engine Oil", International Journal of Engineering and Technology Research, Volume 2, Issue 9, pp. 1 -11,

[22] Rudnick, L.R. (Editor) "Lubricant Additives: Chemistry and Applications" 2nd Edition. CRC Press, Taylor \& Francis group, New York, 2009.

[23] Nehal S. Ahmed and Amal M. Nassar, 2011, "Lubricating Oil Additives: a chapter in Tribology -
Lubricants and Lubrication", Egyptian Petroleum Research Institute, Egypt, p.p.250-268.

[24] Kavindra Singh, Amit Suhane, 2016, "Effect of additive addition in base oil of a lubricant - A Review", International Research Journal of Engineering and Technology, India, Volume 3, Issue 4, p.p.2636-2639.

[25] Jukić, A., Marko Rogošić and Zvonimir Janović, 2007, "Optimization of Alkyl Methacrylate Terpolymer Properties as Lubricating Oil Rheology Modifier", Ind. Eng. Chem. Res., Volume 46, Issue 10, pp.3321-3327.

[26] Nehal S. Ahmed, Amal M. Nassar, 2009, "Lubricating Oil Additives Based on Poly alkyl polyamines", International Journal of Polymeric Materials and Polymeric Biomaterials, Volume 58, Issue 3, pp. 170-198.

[27] Pranab, G., Das Tapan and Das Moumita, 2011, "Evaluation of Poly (acrylates) and their copolymer as viscosity modifiers", Res. J. Chem. Sci., Volume 1, Issue 3,pp.18-25.

[28] Nehal S. Ahmed, Amal M. Nassar, R.M. Nasser, A.F. Khattab, and A.A. Abdel-Azim, 2008, "Synthesis and Evaluation of some polymeric compounds as pour point depressants and viscosity index Improvers for lube oil", journal of petroleum science and technology, Volume 26, Issue 12, pp. 1390-1402.

\title{
دراسة مقارنة لتأثير أنواع مختلفة من البوليمرات على مؤثر اللزوجة ونقطة الانسكاب لزيوت الاساس العراقية
}

\author{
رسل فيصل عبدالصاحب و مهند عبدالرزلق محمد \\ جامعة النهرين
}

الخلاصة

في هذا البحث، تمت دراسة آثار مزج البوليمرات المشتقه من الاكريليت وتحديدا ( بولي ديكين الاكريليت غير المتفرع و بولي اوكتيل الاكربليت المتفرع) على معامل اللزوجة ونقطة الانسكاب لزيوت الاساس العراقيه 40 و 60. تم استخدام التلوين كمذيب و حامل لكلا البوليمرين. ان مستوى التحسن في كل من معامل اللزوجة و نقطة الانسكاب الناتج عن مزج الزيوت مع البوليمرات المشتقه من الأكريليت تم تقييمه استتادا على مقارنته مع القيم المستحصل عليها عند مزج الزيوت مع مضاف محسن لزوجة ونقطة الانسكاب تجاري. ان المضاف التجاري هو مضاف معتمد من قبل مصفى الدورة يتكون من اولوفين كوبوليمر و حامل غير معروفين. كل المضافات الثلاثه تم خلطها بنسب وزنيه (2،2،6،8،10، ) مع كل نوع من انواع زيوت الأساس. وكانت نتيجة الدراسة أن التحسن في مؤثر اللزوجة ونقطة الانسكاب لزيوت الأساس العراقية يكون ذو قيمة اعلى عند استخدام مشتقات الأكريليت عند مقارنتها بمستوى التحسن عند استخدام المضاف التجاري الكلمات الدالة: زيوت, معامل اللزوجة, نقطة الصب, بول اكريليت 